\title{
Post-Transplantation Diabetes Mellitus in Pediatric Patients
}

\author{
Jody B. Grundman ${ }^{\text {a }}$ Joseph I. Wolfsdorf ${ }^{\mathrm{b}}$ Brynn E. Marks ${ }^{\mathrm{a}, \mathrm{c}}$ \\ aDivision of Endocrinology, Children's National Hospital, Washington, DC, USA; 'Division of Endocrinology, Boston \\ Children's Hospital, Boston, MA, USA; ' George Washington University School of Medicine, Washington, DC, USA
}

\section{Keywords}

Post-transplantation diabetes · Immunosuppression ·

Pediatric $\cdot$ Solid organ transplant

\begin{abstract}
More than $80 \%$ of pediatric solid organ transplant (SOT) recipients now survive into young adulthood and many encounter transplant-related complications. Post-transplantation diabetes mellitus (PTDM), sometimes also referred to as post-transplant diabetes or new onset diabetes after transplant, occurs in 3-20\% of pediatric SOT recipients depending upon the organ transplanted, age at transplantation, immunosuppressive regimen, family history, and time elapsed since transplant. To diagnose PTDM, hyperglycemia must persist beyond the initial hospitalization for transplantation when a patient is on stable doses of immunosuppressive medications. Though standard diagnostic criteria used by the American Diabetes Association (ADA) to diagnose diabetes are employed, clinicians need to be aware of the limitations of using these criteria in this unique patient population. Management of PTDM parallels strategies used for type 2 diabetes (T2D), while also carefully considering comorbidities and potential interactions with immunosuppressive medications in these patients. In caring for patients with
\end{abstract}

PTDM, it is important to be familiar with these interactions and comorbidities in order to coordinate care with the transplant team and optimize outcomes for these patients.

(c) 2021 S. Karger AG, Basel

\section{Introduction}

Solid organ transplantation (SOT) is the preferred treatment for most children with end-stage organ failure [1]. Data from the Organ Procurement and Transplant Network (OPTN) accessed on January 11, 2020, show that 1,923 of the 39,719 SOT performed in the USA in 2019 were in patients under 18 years. Advances in surgical technique, immunosuppressive regimens, antiviral prophylaxis, and donor selection have all contributed to improved patient and graft survival (Table 1) [2]. Though the number of pediatric SOT recipients has remained steady over the past 20 years, these advances have resulted in an increased number of patients reaching young adulthood and encountering more transplantation-related complications, including hypertension, dyslipidemia, post-transplantation diabetes mellitus (PTDM), chronic kidney disease, infection, growth suppression, and malignancy [3]. The development of PTDM is associated with 
Table 1. Number of pediatric transplants in 2020 in the USA and survival rates based on OPTN data for transplants performed between 2008 and 2015 (accessed January 12, 2021).

\begin{tabular}{|c|c|c|c|c|c|c|}
\hline Transplanted organ & $\begin{array}{l}\text { Patient } \\
\text { age, yr }\end{array}$ & $\begin{array}{l}\text { Number of } \\
\text { transplants } \\
\text { per year }\end{array}$ & $\begin{array}{l}1 \text { Year } \\
\text { survival, \% }\end{array}$ & $\begin{array}{l}3 \text { Year } \\
\text { survival, \% }\end{array}$ & $\begin{array}{l}5 \text { Year } \\
\text { survival, \% }\end{array}$ & $\begin{array}{l}\text { Incidence } \\
\text { rate of PTDM* }\end{array}$ \\
\hline Liver & $\begin{array}{c}1-5 \\
6-10 \\
11-17\end{array}$ & $\begin{array}{r}278 \\
62 \\
121\end{array}$ & $\begin{array}{l}94.3 \\
96.3 \\
95.2\end{array}$ & $\begin{array}{l}89.3 \\
93.5 \\
92.6\end{array}$ & $\begin{array}{l}85.4 \\
93.5 \\
86.6\end{array}$ & $\begin{array}{l}10.0 \text { per } 1,000 \\
\text { person-years }\end{array}$ \\
\hline Intestine & $\begin{array}{c}1-5 \\
6-10 \\
11-17\end{array}$ & $\begin{array}{r}16 \\
7 \\
6\end{array}$ & $\begin{array}{l}87.3 \\
93.5 \\
82.6\end{array}$ & $\begin{array}{l}77.2 \\
85.2 \\
73.9\end{array}$ & $\begin{array}{l}63.7 \\
82.3 \\
65.0\end{array}$ & \\
\hline
\end{tabular}

Incidence rate of PTDM by organ type as reported in a single-center study with a median of 9.2 years of follow-up after SOT [4]. * Denotes that survival rates were not computed due to a sample size of less than 10. OPTN, organ procurement and transplant network; SOT, solid organ transplant; PTDM, post-transplantation diabetes mellitus.

increased risk for long-term complications including cardiovascular disease, infection, graft loss, and mortality [4, 5].

PTDM occurs in $3-20 \%$ of pediatric transplant patients depending upon the organ transplanted, age at transplantation, immunosuppressive regimen, family history, and lifestyle factors [6-10]. To diagnose PTDM, hyperglycemia must persist beyond the initial hospitalization for transplantation and continue when a patient is on stable doses of immunosuppressive agents. Though standard diagnostic criteria used by the American Diabetes Association (ADA) to diagnose diabetes are employed, clinicians need to be aware of the limitations of these criteria. Management of PTDM parallels strategies used for type 2 diabetes (T2D), while also considering interactions with the immunosuppressive medications and comorbidities in these patients. Clinicians caring for patients with PTDM must be familiar with these interactions and comorbidities in order to coordinate care with the transplant team and optimize outcomes for these patients. In preparing the manuscript, we conducted a systematic electronic search using PubMed (date ranges October 15, 2020-December 15, 2020). Bibliographies from these articles were also searched. There was no restriction based on the language.

\section{Main Text}

Starzl first recognized hyperglycemia following SOT in 1964 [11]. Nearly 40 years later in 2003, the first International Consensus Guidelines for diagnosis and management of diabetes after SOT recommended using the term new onset diabetes after transplant (NODAT) [12]. At a second International Consensus Meeting in 2014, the nomenclature was changed to PTDM [13] due to concerns that variations in screening practices may have resulted in failure to diagnose diabetes before transplantation.

Recently, the appropriateness of the term PTDM has been challenged as many patients, including those receiving SOT for end-stage diabetic nephropathy, are known 
Table 2. Methods for diagnosing PTDM

\begin{tabular}{|c|c|c|}
\hline Diagnostic test & Criteria & Notes \\
\hline FPG & $\geq 126 \mathrm{mg} / \mathrm{dL}^{*}$ & $\begin{array}{l}\text { - Simple to perform } \\
\text { - Unreliable, as glucocorticoid therapy causes worsening hyperglycemia as the day progresses }\end{array}$ \\
\hline Random plasma glucose & $\geq 200 \mathrm{mg} / \mathrm{dL}$ & $\begin{array}{l}\text { - Simple to perform } \\
\text { - Can be done at any time of day }\end{array}$ \\
\hline OGTT & $\geq 200 \mathrm{mg} / \mathrm{dL}^{* *}$ & $\begin{array}{l}\text { - Requires the most time and resources } \\
\text { - Can diagnose impaired glucose tolerance, which is associated with long-term outcomes in SOT } \\
\text { recipients } \\
\text { - Better sensitivity than FPG and A1c }\end{array}$ \\
\hline Alc & $\geq 6.5 \%$ & $\begin{array}{l}\text { - Simple to perform } \\
\text { - Can be done at any time of day } \\
\text { - Unknown if } 6.5 \% \text { cutoff predicts long-term outcomes in PTDM patients } \\
\text { - May under- or overestimate mean blood glucose concentrations, especially in the first-year } \\
\text { posttransplant }\end{array}$ \\
\hline
\end{tabular}

SOT, solid organ transplant; PTDM, post-transplantation diabetes mellitus; OGTT, oral glucose tolerance test; FPG, fasting plasma glucose; A1c, hemoglobin A1C. * Fasting with no caloric intake for at least $8 \mathrm{~h} .{ }^{* *}$ Two hours after glucose load of $1.75 \mathrm{~g} / \mathrm{kg}$ of glucose, maximum $75 \mathrm{~g}$.

to have diabetes before transplantation and outcomes may differ depending on when diabetes developed. With no end date for a diagnosis of PTDM, it also remains unclear whether diabetes diagnosed several years after SOT should be attributed to SOT.

Variations in nomenclature, diagnostic criteria, and immunosuppressive regimens for SOT over time account for significant differences in the reported incidence and complications of PTDM. Furthermore, much of the literature on PTDM focuses on adult renal transplant patients, likely due, at least in part, to the sheer volume of renal transplants. OPTN data accessed January 11, 2020 show that $59.4 \%$ of SOT performed in the USA in 2019 involved a kidney. While guidelines published at the International Consensus meetings mainly focus on PTDM after kidney transplant, they have been largely adopted by other transplant groups for PTDM management [14].

Reports of the incidence of PTDM among pediatric patients have ranged from 3 to $20 \%[6-10,15,16]$. In a retrospective study of 1,364 children in the North American Pediatric Renal Transplant Cooperative, who underwent transplant between 1992 and 1997, time of diagnosis of PTDM ranged from shortly after transplant to 1,212 days posttransplant [6]. Sixty-four percent of patients developed PTDM within the first 6 months after transplantation while receiving higher doses of immunosuppressive medications.

\section{Diagnosis}

PTDM should only be diagnosed after the patient has been discharged from the hospital after SOT and during a stable clinical period with established allograft function on a chronic immunosuppression regimen and free from an acute infection [13]. The oral glucose tolerance test (OGTT) was the gold standard for the diagnosis of PTDM in the 2003 International Consensus Guidelines; however, the most current 2014 guidelines recommend using the standard ADA diagnostic criteria used for people without SOT (Table 2) [12, 13, 19]. There are strengths and weaknesses to each diagnostic test used to detect PTDM, and no single measurement of glycemia has been correlated with long-term outcomes in SOT recipients [13].

Fasting plasma glucose (FPG) alone is unreliable as glucocorticoid therapy, commonly used in SOT patients, tends to cause worsening hyperglycemia as the day progresses [20]. The hemoglobin A1c (A1c) is a simple laboratory test that can be performed at any time of day, but an A $1 c \geq 6.5 \%$ lacks sensitivity for diagnosing PTDM and should not be used as the sole screening test [14, 21, 22]. A1c can under- or overestimate mean blood glucose concentration, especially in the first-year posttransplant [14]. In SOT recipients, the A1c may be falsely elevated due to iron deficiency and uremia (leading to production of cyanate and carbamylated hemoglobin that interferes with the measurement of A1c) [21]. Factors that lead to falsely low A1c values include blood loss, blood cell transfusions, shortened erythrocyte survival time, erythropoietin treatment, and impaired red cell proliferation due to immunosuppressant drugs $[21,23]$. Furthermore, the A1c diagnostic threshold of $\geqq 6.5 \%$ was established based on the risk of developing diabetic retinopathy in people with T2D; it is unknown whether this threshold predicts longterm outcomes in patients with PTDM [24]. 
OGTT identifies more patients than FPG or A1c alone $[13,21]$. In a meta-analysis of kidney transplant patients, the sensitivity of A1c compared to OGTT for diagnosing PTDM was 50\% versus $75 \%$ and specificities were $96 \%$ versus $89 \%$, respectively [22]. OGTT can also be used to diagnose impaired glucose tolerance as defined by a $2-\mathrm{h}$ plasma glucose of 140-199 mg/dL, which also conveys an increased risk for complications in SOT recipients [25]. Though OGTT is the most sensitive diagnostic test, it requires the most time and resources of all the diagnostic options.

\section{Screening}

Adults awaiting SOT should undergo screening for diabetes with intermittent FPG and/or OGTT. However, given vast differences in the prevalence of comorbid diabetes in pediatric versus adult patients, there are no clear screening guidelines in pediatrics. One notable exception is that patients with cystic fibrosis (CF) should have an OGTT in the 6 months prior to transplantation [26]. Prior to transplantation, clinicians should screen SOT patients for a family history of diabetes and for any history of abnormal A1c or impaired glucose tolerance noted on OGTT. Pretransplant counseling about lifestyle modifications, including maintaining a healthy body weight, diet, and exercise, is encouraged for adult SOT patients and is also likely to benefit pediatric patients $[8,27]$.

The 2003 International Consensus Guidelines state that FPG should be checked at least weekly for the first 4 weeks after transplantation, at 3 and 6 months, and then annually. Plasma glucose levels should be monitored at regular follow-up intervals, and OGTT may be performed if the provider believes that it is indicated [12].

\section{Pathophysiology of PTDM}

PTDM results from a combination of insulin resistance and insulin deficiency and shares many risk factors and pathophysiologic aspects with T2D. Decreased insulin release, impaired insulin-mediated glucose uptake and suppression of hepatic glucose output $[28,29]$, dysregulated incretin axis signaling between the gut and pancreas, and other transplantation specific factors, including hypomagnesemia linked to calcineurin inhibitors (CNI), may all contribute to the development of PTDM [29-31]. As with many other aspects of PTDM, data about risk factors for its development in pediatric patients are limited. Data from adults comes largely from renal transplant patients and offers some insight into risk factors in the pediatric population.

\section{The Role of Immunosuppression}

Immunosuppressants are a key component of managing post-transplant patients. Regimen selection is influenced by many factors, including the type of transplant and age and health of the recipient. SOT recipients are commonly treated with an immunosuppressant regimen that includes some combination of corticosteroids, CNI, and mycophenolate mofetil (MMF) or azathioprine. The proposed mechanisms of how these agents influence PTDM are listed in Table 3. Though the immunosuppressive regimens used in pediatric transplant patients are similar to those used in adults, pediatric patients experience decreased absorption and faster metabolism and clearance of these drugs, and therefore require higher doses to obtain adequate trough levels $[32,33]$.

\section{Corticosteroids}

Corticosteroids have a dose-dependent, causal association with PTDM; however, the impact of complete steroid withdrawal on PTDM remains unclear. Analysis of 2,726 pediatric kidney transplant patients in the OPTN database showed that steroid use at discharge was an independent risk factor for PTDM (HR 3.573, $p=0.03$ ) [34]. Long-term double-blind randomized controlled trials in adults showed that early corticosteroid withdrawal had a limited impact on reducing PTDM when compared to low-dose prednisone ( $5 \mathrm{mg} /$ day) $[35,36]$.

\section{Calcineurin Inhibitors}

CNIs, including tacrolimus and cyclosporine, as well as inhibitors of mammalian target of rapamycin, sirolimus, and everolimus (see below), lead to a dose-dependent decrease in insulin synthesis and secretion [37]. In a study evaluating insulinoma $\beta$-cells in vitro and in pancreases of obese and lean Zucker rats, tacrolimus was shown to reduce insulin content and secretion, but when it was withdrawn or replaced by cyclosporine, these effects reversed, suggesting that tacrolimus-induced $\beta$-cell dysfunction may be potentially reversible [38].

In the North American pediatric renal transplant cooperative study (NAPRTCS) dataset, after the approval of tacrolimus for use in kidney recipients in 1996, rates of use rose from 3\% in 1996 to 45\% in 1997 [6]. A disproportionately greater number of patients treated with tacrolimus developed PTDM. Analysis of the Studies of Pediatric Liver Transplantation (SPLIT) database, a registry that includes 3,161 patients from 44 centers in the US and Canada, showed that of the 214 pediatric liver transplant patients who developed PTDM, $14.2 \%$ were on tacrolimus compared to $5.5 \%$ on cyclosporine therapy $(p<$ 
Table 3. Proposed diabetogenic mechanisms of immunosuppressants commonly used in SOT recipients

\begin{tabular}{|c|c|c|}
\hline Corticosteroids & $\begin{array}{l}\text { - Decrease peripheral insulin sensitivity } \\
\text { - Decrease number of insulin receptors and their affinity for insulin } \\
\text { - Increase hepatic gluconeogenesis } \\
\text { - Decrease insulin synthesis } \\
\text { - Inhibit pancreatic insulin secretion }\end{array}$ & $\begin{array}{l}\text { - Dose-dependent } \\
\text { - Impact of complete withdrawal is unclear }\end{array}$ \\
\hline Tacrolimus & $\begin{array}{l}\text { - Decrease insulin synthesis } \\
\text { - Decrease insulin secretion } \\
\text { - Increase } \beta \text {-cell apoptosis }\end{array}$ & $\begin{array}{l}\text { - Dose-dependent } \\
\text { - } \beta \text {-cell dysfunction may be reversible }\end{array}$ \\
\hline Sirolimus & $\begin{array}{l}\text { - Decrease peripheral insulin sensitivity } \\
\text { - Increase } \beta \text {-cell apoptosis } \\
\text { - Impair pancreatic proliferation }\end{array}$ & - Dose-dependent \\
\hline
\end{tabular}

SOT, solid organ transplant; PTDM, post-transplantation diabetes mellitus.

0.0001) [9]. Among adult renal SOT recipients, the prevalence of PTDM is decreasing over time as lower doses of CNI's are used [39].

\section{Antimetabolites}

The use of azathioprine and MMF has not been associated with increased risk for developing PTDM and may reduce the diabetogenic effect of tacrolimus; however, studies have shown mixed results [40]. Evidence suggests that inclusion of antimetabolites in the immunosuppressive regimen allows for lower doses of CNIs and corticosteroids, the diabetogenic immunosuppressant medications, thereby decreasing the overall risk of PTDM [41]. Among 381 pediatric heart transplant recipients, there was no difference in the prevalence of PTDM among those treated with MMF versus azathioprine [9].

Mammalian Target of Rapamycin (mTOR) Inhibitors

Sirolimus, also known as rapamycin, is an mTOR inhibitor commonly used in SOT. Data from more than 20,000 renal SOT recipients who used steroid-sparing regimens show that patients treated with sirolimus had a nearly 2-fold increased risk of developing PTDM regardless of the other immunosuppressants used [42].

\section{Other Risk Factors}

Hyperglycemia in the immediate post-transplantation period has been reported in approximately $15 \%$ of pediatric SOT patients without known diabetes and, of those, $40 \%$ subsequently developed PTDM [43]. Children un- dergoing lung transplantation were at 4-times greater risk (36\%) of developing diabetes relative to other single organ transplants (kidney $8.3 \%$, liver $3.4 \%$, and heart 1.6\%); however, the increased risk is primarily due to the effects of $\mathrm{CF}$, which is the most common indication for lung transplantation. After excluding patients with CF, the risk for hyperglycemia after lung transplantation was only 1.3 times higher than the risk for kidney recipients. All children who developed diabetes had hyperglycemia within 2 months of transplantation and 33\% of children with hyperglycemia had at least 1 episode of rejection before developing hyperglycemia.

Up to $30 \%$ of adolescents with CF will develop CFrelated diabetes [44]. Although a diagnosis of CF-related diabetes prior to transplantation increased the risk of death while awaiting lung transplantation, it had no impact on survival after transplantation [45]. Among adults without diabetes before lung transplantation, a diagnosis of CF increased the risk of developing diabetes by 3.3 times [46].

Both the adult and pediatric literature have shown a clear association between PTDM and pre-transplantation BMI and age at transplantation [47, 48]. Large-scale studies of pediatric heart, kidney, and liver transplant recipients have shown an increased risk for PTDM among African Americans, older SOT recipients, and those with a higher BMI at the time of transplantation $[48,49]$. Single nucleotide polymorphisms associated with $\beta$-cell apoptosis convey a higher risk for PTDM in adult SOT recipients, but have not been studied in pediatric patients [50]. 
Both the adult and pediatric transplant literature indicate that hypomagnesemia confers an increased risk for the development of PTDM $[47,51]$ and a meta-analysis has shown improvements in glycemic control in adult SOT patients supplemented with magnesium [52].

\section{Treatment}

There are no glycemic targets established for the immediate posttransplant period and practices vary among transplant centers. Intravenous insulin therapy is typically required during this period due to frequently titrated high-dose immunosuppressant medications, fluctuating nutritional status, and altered renal function which impacts insulin clearance [53]. The glycemic target of 140$180 \mathrm{mg} / \mathrm{dL}$ is commonly used; however, the more stringent goal of 110-140 mg/dL may be appropriate if it can be achieved without frequent or severe hypoglycemia [54]. Data suggest that early insulin therapy after transplantation in adult kidney recipients improves $\beta$-cell function and decreases the incidence of PTDM [55].

Glycemic targets and long-term treatment of PTDM are rooted in adult T2D guidelines. An A1c $<7 \%$ is recommended for most adults with diabetes, including PTDM, because this target reduces long-term microvascular complications [24]. However, evidence suggests that microvascular complications progress more rapidly in SOT patients and, therefore, goals should be individualized depending on life expectancy and the frequency of hypoglycemia [56]. Continuous glucose monitoring has been used to monitor glycemia in the early post-transplantation period in adult pancreas transplant recipients, but has not been widely used [57]. Currently, there are no established goals for time-in-range $(70-180 \mathrm{mg} / \mathrm{dL})$ in SOT patients; however, International Consensus Guidelines suggest a target of $\geq 70 \%$ time-in-range for most patients with diabetes as this correlates with A1c $\leq 7 \%$ and decreased risk of microvascular complications [58].

While there is some evidence that certain immunosuppressive regimens are associated with a lower risk of PTDM [59], the limited evidence must be carefully weighed against the risk for graft loss. Tacrolimus has been associated with a higher risk of PTDM; however, rates of graft rejection are lower as compared to patients treated with cyclosporine $[49,59]$. Given mixed findings about the efficacy of adjusting immunosuppressive regimens for management of PTDM and the potential for graft loss, the latest Consensus Guidelines recommend against adjusting immunosuppressive therapy specifically to treat PTDM [13].
Although lifestyle modifications are a central tenet of treatment of T2D in pediatrics, there is a limited evidence to support its utility in PTDM. Pharmacological treatment of PTDM must carefully consider side-effect profiles, drug-drug interactions, glomerular filtration rate (GFR), and evidence supporting the use of specific agents in PTDM. Most drug-drug interactions are caused by medications that inhibit or induce cytochrome P450 3A4 (CYP3A4), which plays an important role in metabolizing CNIs [60]. To date, there are no studies to assesses optimal pharmacological therapy in PTDM; however, several different classes of medications have been studied in adult SOT recipients, including metformin, insulin, sulfonylureas, glinides, thiazolidinediones, dipeptidyl peptidase- 4 inhibitors, glucagon-like peptide 1 agonists (GLP1), and sodium/glucose cotransporter 2 inhibitors [61]. Currently, there are only a limited number of FDAapproved treatment options for pediatric T2D, including insulin, metformin, and the GLP1 agonist liraglutide. These medications are often used off-label for management of pediatric PTDM because, at the present time, there are no FDA-approved medications for treatment of pediatric PTDM. Many ongoing studies are exploring the use of additional classes of medications for pediatric T2D; however, it will undoubtedly take some considerable amount of time before their safety and efficacy in pediatric PTDM is known.

Metformin is the first-line therapy for pediatric T2D patients; it improves insulin sensitivity and decreases hepatic gluconeogenesis and tends to have little effect on body weight [19]. Metformin is not metabolized by CYP3A4 and does not interact with immunosuppressive medications; however, it is cleared by the kidney, often causes gastrointestinal side effects and, rarely, has the potential to cause lactic acidosis. Dose adjustments are necessary as renal function changes, and given the risk for lactic acidosis, use should be discontinued during periods of an acute illness. A systematic review of data from adults with CKD and T2D suggests that dose adjustments are not necessary until the GFR is $<45 \mathrm{~mL} / \mathrm{min} / \mathrm{m}^{2}$ [62].

Insulin therapy does not pose a risk for drug-drug interactions, though renal function must be considered as insulin is metabolized by the kidney. Dose adjustments typically are not necessary when the GFR is $>60 \mathrm{~mL} /$ $\min / 1.73 \mathrm{~m}^{2}$; however, progressive dose reductions are necessary to avoid hypoglycemia as renal function declines below this level [53].

GLP1 agonists increase glucose-mediated insulin secretion, inhibit glucagon secretion, decrease hepatic gluconeogenesis, and delay gastric emptying. They have also 
been shown to have renal and cardiovascular-protective effects in adults with T2D, which is important to consider given that renal and cardiovascular disease are common comorbidities in SOT patients [63]. Specifically, in PTDM, in vitro studies have shown that GLP1 agonists promote $\beta$-cell protection from both glucocorticoids and CNIs [64]. In a study of 63 adult SOT patients, GLP1 therapy was associated with weight loss and a sustained reduction in A1c of $0.6 \%$ over 2 years [63]. There are no studies exploring the impact of liraglutide in pediatric PTDM patients.

\section{Long-Term Outcomes}

Few studies have explored whether PTDM resolves over time. Although some studies have suggested that rates of resolution may exceed $50 \%$, it must be noted that, contrary to recommendations from International Consensus Guidelines, these studies categorized patients as having PTDM shortly after transplant $[6,24,65]$. Therefore, it is highly likely that these studies included many patients with stress-induced, transient hyperglycemia rather than true PTDM. Clinical experience suggests that most patients diagnosed with PTDM require long-term antihyperglycemic therapy.

In adults, PTDM is associated with increased morbidity and mortality in all types of SOT. Rates of sepsis, renal failure, cardiovascular disease, and infection are increased while rates of graft loss are accelerated and the prevalence of chronic rejection is increased $[5,66,67]$. In a study of 11,000 adults who received a kidney between 1996 and 2000 , among those with PTDM there was a $63 \%$ increased risk of graft failure, $46 \%$ increased risk of death-censored graft failure, and $87 \%$ increased risk of mortality [40].

In pediatric SOT recipients, there was a 3-fold increased risk of death among those with PTDM as compared to healthy age matched Canadian children [4]. The pediatric data are extremely limited. Most evidence about long-term outcomes in SOT recipients with PTDM comes from adult kidney transplant recipients and the quality of evidence is limited by the lack of consistency in diagnosis of and screening for PTDM. To date, evidence is lacking about, whether optimizing glycemic control in PTDM improves outcomes.

\section{Conclusion}

Variations in terminology, diagnostic criteria, and practices among transplant centers coupled with a lack of long-term surveillance have limited the ability to accu- rately determine the prevalence of PTDM and optimal diagnostic and management approaches in pediatric SOT recipients. Although standard ADA diagnostic criteria and management goals are applied to SOT recipients with PTDM, there is a lack of robust evidence-based data to support these practices. As more pediatric SOT recipients survive into adulthood, it is imperative that high-quality studies are designed to provide the evidence to inform optimal management and data on long-term outcomes. For now, clinicians should be mindful of the limitations of each diagnostic test for PTDM and must carefully consider the effects of specific immunosuppressive regimens and comorbidities of SOT in tailoring an appropriate PTDM treatment regimen for each patient.

\section{Conflict of Interest Statement}

The authors have no conflicts of interest to declare.

\section{Funding Sources}

Dr. Brynn E. Marks has received grant funding from the Pediatric Endocrine Society, Tandem Diabetes Care, Inc., the Cystic Fibrosis Foundation, and the Boston Children's Academy for Teaching and Educational Innovation and Scholarship.

\section{Author Contributions}

B.E.M. and J.I.W. conducted initial literature review and wrote the outline for the manuscript. The initial draft of the manuscript was written by B.E.M. and J.B.G. All authors reviewed and revised the manuscript.

\section{References}

1 Magee JC, Krishnan SM, Benfield MR, Hsu DT, Shneider BL. Pediatric transplantation in the United States, 1997-2006. Am J Transplant. 2008;8(4 Pt 2):935-45.

2 Chinnakotla S, Verghese P, Chavers B, Rheault MN, Kirchner V, Dunn T, et al. Outcomes and risk factors for graft loss: lessons learned from 1,056 pediatric kidney transplants at the University of Minnesota. J Am Coll Surg. 2017;224(4):473-86.

3 Larosa C, Baluarte HJ, Meyers KE. Outcomes in pediatric solid-organ transplantation. $\mathrm{Pe}$ diatr Transplant. 2011;15(2):128-41.

4 Chanchlani R, Kim SJ, Dixon SN, Jassal V, Banh T, Borges K, et al. Incidence of new-onset diabetes mellitus and association with mortality in childhood solid organ transplant recipients: a population-based study. Nephrol Dial Transplant. 2019;34(3):524-31. 
5 Hjelmesæth J, Hartmann A, Leivestad T, Holdaas H, Sagedal S, Olstad M, et al. The impact of early-diagnosed new-onset posttransplantation diabetes mellitus on survival and major cardiac events. Kidney Int. 2006; 69(3):588-95.

6 Al-Uzri A, Stablein DM, A Cohn R. Posttransplant diabetes mellitus in pediatric renal transplant recipients: A report of the North American pediatric renal transplant cooperative study (NAPRTCS). Transplantation. 2001;72(6):1020-4.

7 Prokai A, Fekete A, Kis E, Reusz GS, Sallay P, Korner A, et al. Post-transplant diabetes mellitus in children following renal transplantation. Pediatr Transplant. 2008;12(6):643-9.

8 Greig F, Rapaport R, Klein G, Akler G, Annunziato R, Miloh T, et al. Characteristics of diabetes after pediatric liver transplant. Pediatr Transplant. 2013;17(1):27-33.

9 Hathout E, Alonso E, Anand R, Martz K, Imseis E, Johnston J, et al. Post-transplant diabetes mellitus in pediatric liver transplantation. Pediatr Transplant. 2009 Aug;13(5):599-605.

10 Wagner K, Webber SA, Kurland G, Boyle GJ, Miller SA, Cipriani L, et al. New-onset diabetes mellitus in pediatric thoracic organ recipients receiving tacrolimus-based immunosuppression. J Heart Lung Transplant. 1997; 16(3):275-82.

11 Starzl TE, Marchioro TL, Rifkind D, Holmes $\mathrm{JH}$, Rowlands DT Jr, Waddell WR. Factors in successful renal transplantation. Surgery. 1964;56:296-318.

12 Davidson J, Wilkinson A, Dantal J, Dotta F, Haller H, Hernández D, et al. New-onset diabetes after transplantation: 2003 international consensus guidelines. Transplantation. 2003; 75(10):3-24.

13 Sharif A, Hecking M, de Vries AP, Porrini E, Hornum M, Rasoul-Rockenschaub S, et al. Proceedings from an international consensus meeting on posttransplantation diabetes mellitus: recommendations and future directions. Am J Transplant. 2014;14(9):19922000.

14 Shivaswamy V, Boerner B, Larsen J. Posttransplant diabetes mellitus: causes, treatment, and impact on outcomes. Endocr Rev. 2016;37(1):37-61.

15 Furth S, Neu A, Colombani P, Plotnick L, Turner ME, Fivush B. Diabetes as a complication of tacrolimus (FK506) in pediatric renal transplant patients. Pediatr Nephrol. 1996; 10(1):64-6.

16 McKee M, Segev D, Wise B, Case B, Neu A, Fivush B, et al. Initial experience with FK506 (tacrolimus) in pediatric renal transplant recipients. J Pediatr Surg. 1997;32(5):688.

17 American Diabetes Association. 13. Children and adolescents: Standards of medical care in diabetes-2020. Diabetes Care. 2020;43(Suppl 1):S163-82.
18 Burt MG, Roberts GW, Aguilar-Loza NR, Frith P, Stranks SN. Continuous monitoring of circadian glycemic patterns in patients receiving prednisolone for COPD. J Clin Endocrinol Metab. 2011;96(6):1789-96.

19 Werzowa J, Hecking M, Haidinger M, Döller $\mathrm{D}$, Sharif A, Tura A, et al. The diagnosis of posttransplantation diabetes mellitus: meeting the challenges. Curr Diab Rep. 2015;15(5): 27.

20 Pimentel AL, Cavagnolli G, Camargo JL. Diagnostic accuracy of glycated hemoglobin for post-transplantation diabetes mellitus after kidney transplantation: systematic review and meta-analysis. Nephrol Dial Transplant. 2017;32(3):565-72.

21 Hare MJ, Shaw JE, Zimmet PZ. Current controversies in the use of haemoglobin A1c. J Intern Med. 2012;271(3):227-36.

22 Turner R. Intensive blood-glucose control with sulphonylureas or insulin compared with conventional treatment and risk of complications in patients with type 2 diabetes (UKPDS 33). Lancet. 1998;352(9131):837-53.

23 Valderhaug TG, Hjelmesæth J, Hartmann A, Røislien J, Bergrem HA, Leivestad T, et al. The association of early post-transplant glucose levels with long-term mortality. Diabetologia. 2011;54(6):1341-9.

24 Moran A, Brunzell C, Cohen RC, Katz M, Marshall BC, Onady G, et al. Clinical care guidelines for cystic fibrosis-related diabetes: a position statement of the American diabetes association and a clinical practice guideline of the cystic fibrosis foundation, endorsed by the pediatric endocrine society. Diabetes Care. 2010;33(12):2697-708.

25 Garro R, Warshaw B, Felner E. New-onset diabetes after kidney transplant in children. Pediatr Nephrol. 2015;30(3):405-16.

26 Buyan N, Bilge I, Turkmen MA, Bayrakci U, Emre S, Fidan K, et al. Post-transplant glucose status in 61 pediatric renal transplant recipients: preliminary results of five Turkish pediatric nephrology centers. Pediatr Transplant. 2010;14(2):203-11.

27 Jørgensen MB, Hornum M, van Hall G, Bistrup C, Hansen JM, Mathiesen ER, et al. The impact of kidney transplantation on insulin sensitivity. Transpl Int. 2017;30(3):295-304.

28 Hecking M, Kainz A, Werzowa J, Haidinger M, Döller D, Tura A, et al. Glucose metabolism after renal transplantation. Diabetes Care. 2013;36(9):2763-71.

29 Halden TA, Egeland EJ, Åsberg A, Hartmann A, Midtvedt K, Khiabani HZ, et al. GLP-1 restores altered insulin and glucagon secretion in posttransplantation diabetes. Diabetes Care. 2016;39(4):617-24.

30 Prokai A, Fekete A, Pasti K, Rusai K, Banki NF, Reusz G, et al. The importance of different immunosuppressive regimens in the development of posttransplant diabetes mellitus. Pediatr Diabetes. 2012;13(1):81-91.
31 Jain AB, Fung JJ, Tzakis AG, Venkataramanan R, Abu-Elmagd K, Alessiani M, et al. Comparative study of cyclosporine and FK 506 dosage requirements in adult and pediatric orthotopic liver transplant patients. Transplant Proc. 1991;23(6):2763-6.

32 Kuo HT, Poommipanit N, Sampaio M, Reddy P, Cho YW, Bunnapradist S. Risk factors for development of new-onset diabetes mellitus in pediatric renal transplant recipients: an analysis of the OPTN/UNOS database. Transplantation. 2010;89(4):434-9.

33 Pirsch JD, Henning AK, First MR, Fitzsimmons W, Gaber AO, Reisfield R, et al. Newonset diabetes after transplantation: results from a double-blind early corticosteroid withdrawal trial. Am J Transplant. 2015; 15(7):1982-90.

34 Woodle ES, First MR, Pirsch J, Shihab F, Gaber AO, Van Veldhuisen P. A prospective, randomized, double-blind, placebo-controlled multicenter trial comparing early (7 day) corticosteroid cessation versus longterm, low-dose corticosteroid therapy. Ann Surg. 2008;248(4):564-77.

35 Øzbay LA, Smidt K, Mortensen DM, Carstens J, Jørgensen KA, Rungby J. Cyclosporin and tacrolimus impair insulin secretion and transcriptional regulation in INS-1E beta-cells. $\mathrm{Br}$ J Pharmacol. 2011;162(1):136-46.

36 Triñanes J, Rodriguez-Rodriguez AE, BritoCasillas Y, Wagner A, de Vries APJ, Cuesto G, et al. Deciphering tacrolimus-induced toxicity in pancreatic $\beta$ cells. Am J Transplant. 2017;17(11):2829-40.

37 Hart A, Smith JM, Skeans MA, Gustafson SK, Wilk AR, Castro S, et al. OPTN/SRTR 2017 annual data report: kidney. Am J Transplant. 2019;19(Suppl 2):19-123.

38 Kasiske BL, Snyder JJ, Gilbertson D, Matas AJ. Diabetes mellitus after kidney transplantation in the United States. Am J Transplant. 2003; 3(2): $178-85$.

39 Jaber JJ, Feustel PJ, Elbahloul O, Conti AD, Gallichio MH, Conti DJ. Early steroid withdrawal therapy in renal transplant recipients: a steroid-free sirolimus and cellcept-based calcineurin inhibitor-minimization protocol. Clin Transplant. 2007;21(1):101-9.

40 Johnston O, Rose CL, Webster AC, Gill JS. Sirolimus is associated with new-onset diabetes in kidney transplant recipients. J Am Soc Nephrol. 2008;19(7):1411-8.

41 Chanchlani R, Joseph Kim S, Kim ED, Banh $\mathrm{T}$, Borges K, Vasilevska-Ristovska J, et al. Incidence of hyperglycemia and diabetes and association with electrolyte abnormalities in pediatric solid organ transplant recipients. Nephrol Dial Transplant. 2017;32(9):1579_ 86.

42 Cystic Fibrosis Foundation. Cystic fibrosis foundation patient registry 2017 annual data report. Bethesda, MD; 2018. 
43 Hayes D, Patel AV, Black SM, McCoy KS, Kirkby S, Tobias JD, et al. Influence of diabetes on survival in patients with cystic fibrosis before and after lung transplantation. J Thorac Cardiovasc Surg. 2015;150(3):707-e2.

44 Ye X, Kuo HT, Sampaio MS, Jiang Y, Bunnapradist $\mathrm{S}$. Risk factors for development of new-onset diabetes mellitus after transplant in adult lung transplant recipients. Clin Transplant. 2011;25(6):885-91.

45 Hayes W, Boyle S, Carroll A, Bockenhauer D, Marks SD. Erratum to: hypomagnesemia and increased risk of new-onset diabetes mellitus after transplantation in pediatric renal transplant recipients. Pediatr Nephrol. 2017;32(5): 903-84.

46 Sparks JD, Cantor RS, Pruitt E, Kirklin JK, Carboni M, Dreyer W, et al. New-onset diabetes after pediatric heart transplantation: a review of the pediatric heart transplant study. Pediatr Transplant. 2019;23(5):e13476.

47 Kuo HT, Lau C, Sampaio MS, Bunnapradist S. Pretransplant risk factors for new-onset diabetes mellitus after transplant in pediatric liver transplant recipients. Liver Transpl. 2010;16(11):1249-56.

48 McCaughan JA, McKnight AJ, Maxwell AP. Genetics of new-onset diabetes after transplantation. J Am Soc Nephrol. 2014;25(5): 1037-49.

49 Cheungpasitporn W, Thongprayoon C, Harindhanavudhi T, Edmonds PJ, Erickson SB. Hypomagnesemia linked to new-onset diabetes mellitus after kidney transplantation: a systematic review and meta-analysis. Endocr Res. 2016;41(2):142-7.

50 Simental-Mendía LE, Sahebkar A, RodríguezMorán M, Guerrero-Romero F. A systematic review and meta-analysis of randomized controlled trials on the effects of magnesium supplementation on insulin sensitivity and glucose control. Pharmacol Res. 2016;111:27282.

51 Iyengar R, Franzese J, Gianchandani R. Inpatient glycemic management in the setting of renal insufficiency/failure/dialysis. Curr Diab Rep. 2018;18(10):75.

52 American Diabetes Association. 15. Diabetes care in the hospital: standards of medical care in diabetes-2020. Diabetes Care. 2020; 43(Suppl 1):S193-202.

53 Hecking M, Haidinger M, Döller D, Werzowa J, Tura A, Zhang J, et al. Early basal insulin therapy decreases new-onset diabetes after renal transplantation. J Am Soc Nephrol. 2012; 23(4):739-49.

54 Burroughs TE, Swindle J, Takemoto S, Lentine KL, Machnicki G, Irish WD, et al. Diabetic complications associated with new-onset diabetes mellitus in renal transplant recipients. Transplantation. 2007;83(8):1027-34.

55 Mittal S, Franklin RH, Policola C, Sharples E, Friend PJ, Gough SC. Early postoperative continuous glucose monitoring in pancreas transplant recipients. Transpl Int. 2015;28(5): 604-9.

56 Battelino T, Danne T, Bergenstal RM, Amiel SA, Beck R, Biester T, et al. Clinical targets for continuous glucose monitoring data interpretation: recommendations from the international consensus on time in range. Diabetes Care. 2019;42(8):1593-603.

57 Webster AC, Woodroffe RC, Taylor RS, Chapman JR, Craig JC. Tacrolimus versus ciclosporin as primary immunosuppression for kidney transplant recipients: meta-analysis and meta-regression of randomised trial data. BMJ. 2005;331(7520):810-4.

58 Christians U, Jacobsen W, Benet LZ, Lampen A. Mechanisms of clinically relevant drug interactions associated with tacrolimus. Clin Pharmacokinet. 2002;41(11):813-51.

59 Ahmed SH, Biddle K, Augustine T, Azmi S. Post-transplantation diabetes mellitus. Diabetes Ther. 2020;11(4):779-801.

60 Inzucchi SE, Lipska KJ, Mayo H, Bailey CJ, McGuire DK. Metformin in patients with type 2 diabetes and kidney disease: a systematic review. JAMA. 2014;312(24):2668-75.

61 Singh P, Pesavento TE, Washburn K, Walsh D, Meng S. Largest single-centre experience of dulaglutide for management of diabetes mellitus in solid organ transplant recipients. Diabetes Obes Metab. 2019;21(4):1061-5.

62 Sadhu AR, Schwartz SS, Herman ME. The rationale for use of incretins in the management of new onset diabetes after transplantation (NODAT). Endocr Pract. 2015;21(7):814-22.

63 Paolillo JA, Boyle GJ, Law YM, Miller SA, Lawrence $\mathrm{K}$, Wagner K, et al. Post transplant diabetes mellitus in pediatric thoracic organ recipients receiving tacrolimus-based immunosuppresion. Transplantation. 2001;71(2):252-6.

64 Schnitzler M, Kasiske BL, Snyder JJ, Gilbertson D, Matas AJ. Diabetes mellitus after kidney transplantation in the United States (1) (multiple letters). Am J Transplant. 2003; 3(10): 1318

65 Cosio FG, Kudva Y, Van Der Velde M, Larson TS, Textor SC, Griffin MD, et al. New onset hyperglycemia and diabetes are associated with increased cardiovascular risk after kidney transplantation. Kidney Int. 2005;67(6): 2415-21. 